\title{
Variability of nutrients intake, lipid profile and cardiovascular mortality among geographical areas in Spain: The DRECE study
}

\author{
Agustín Gómez de la Cámara, ${ }^{1,2}$ Eva de Andrés Esteban, ${ }^{1,2}$ Gerard Urrútia Cuchí,,3 \\ Enrique Calderón Sandubete, ${ }^{2,4}$ Miguel Ángel Rubio Herrera, ${ }^{5}$ Miguel Menéndez Orenga, ${ }^{1}$ \\ David Lora Pablos ${ }^{1,2}$

\begin{abstract}
${ }^{1}$ Instituto de Investigación Hospital 12 de Octubre, Madrid; ${ }^{2}$ CIBER Epidemiología y Salud Pública, Madrid; ${ }^{3}$ Hospital Santa Creu i Sant Pau, Barcelona; ${ }^{4}$ Hospital Virgen del Rocio, Sevilla; ${ }^{5}$ Servicio de Endocrinología y Nutrición, Hospital Clínico Universitario de San Carlos, Madrid, Spain
\end{abstract}

\begin{abstract}
It has often been suggested that cardiovascular mortality and their geographical heterogeneity are associated with nutrients intake patterns and also lipid profile. The large Spanish study Dieta y Riesgo de Enfermedades Cardiovasculares en España (DRECE) investigated this theory from 1991 to 2010. Out of the 4,783 Spanish individuals making up the DRECE cohort, 220 subjects (148 men and 72 women) died (4.62\%) during the course of the study. The mean age of patients who died from cardiovascular causes (32 in all) was 61.08 years 95\% CI (57.47-64.69) and
\end{abstract}

Correspondence: Agustín Gómez de la Cámara, Instituto de Investigación Hospital 12 de Octubre, CAA 6 a planta Bloque D, Avda. de Córdoba s/n, 28041 Madrid, Spain.

Tel: +34917792837 .

E-mail: acamara@h12o.es

Key words: Cardiovascular mortality; Geographic variability; Lipid profile; Spatial analysis; Spain.

Conflict of interest: the authors declare no potential conflict of interest.

Contributions: all the authors actively participated in the manuscript preparation, as well as read and approved the final manuscript. All authors listed have contributed sufficiently to the project to be included as authors, and all those who are qualified to be authors are listed in the author by line.

Funding: this project was financially supported by the Instituto de Salud Carlos III (PI14/01940) and Fondo Europeo de Desarrollo Regional (FEDER).

Received for publication: 13 October 2016.

Revision received: 11 July 2017.

Accepted for publication: 11 July 2017.

(C) Copyright A. Gómez de la Cámara et al., 2017

Licensee PAGEPress, Italy

Geospatial Health 2017; 12:524

doi:10.4081/gh.2017.524

This article is distributed under the terms of the Creative Commons Attribution Noncommercial License (CC BY-NC 4.0) which permits any noncommercial use, distribution, and reproduction in any medium, provided the original author(s) and source are credited.
$70.91 \%$ of them were males. The consumption of nutrients and the lipid profile by geographical area, studied by geospatial models, showed that the east and southern area of the country had the highest fat intake coupled to a high rate of unhealthy lipid profile. It was concluded that the spatial geographical analysis showed a relationship between high fat intake, unhealthy lipid profile and cardiovascular mortality in the different geographical areas, with a high variability within the country.

\section{Introduction}

Cardiovascular disease (CVD) is still a major public health problem and the leading cause of death in most of the developed countries (Kattainen, 2006). Previous studies ask for whether differences in the distribution of CVD risk factors between regions could explain geographical differences in the incidence and cardiovascular mortality. The IBERICA study (Moreno, 2001) demonstrates that there is a north-south increasing gradient in the incidence of, and mortality from, ischemic heart disease, and the ERICE study (Gabriel et al., 2008) shows that the distribution of cardiovascular risk factors is heterogeneous in Spain. Paradoxically, the geographic areas with a higher prevalence of CVD risk are mainly located in eastern and southern Spain, including the Mediterranean seaside, i.e. Levante, Andalusia and Extremadura (Gabriel et al., 2008). The variability between different geographical areas is known to be marked with a relevant high prevalence ratio for various risks, among them for hypercholesterolemia, diabetes, obesity, smoking and hypertension (Gabriel et al., 2008; Grau et al., 2011). Epidemiological studies indicate that the quality of diet, together with lifestyle factors, has considerable influence on mortality (Kaluza et al., 2009). Subsequent studies of diet and cardiovascular heart disease (CHD), have since evaluated the effects of numerous dietary nutrients and dietary patterns on CHD risk (Mente et al., 2009). The Seven Countries European Study (Yarnell and Evans, 2000) investigated the distribution of CVD mortality in Europe and found this diagnosis three times higher in some places than in others. This particular study dealt with the interaction of classic CVD risk factors with the dietary habits as well as with their combined effects on the occurrence of CVD, including mortality. The authors essentially point out the role of cholesterol in CVD and note the positive (healthy) influence of the Mediterranean diet with respect to serum cholesterol. More recently, prospective cohort studies and randomised controlled trials (RCTs) have examined these associations in large 
populations with long follow-up periods (Mente et al., 2009) and again emphasised the harmful effect of high concentrations of saturated fats in the diet. In fact, CVD prevention and treatment now focus on dietary recommendations to reduce the intake of saturated fat, primarily as a means of lowering cholesterol concentrations of the low-density lipoprotein (LDL) type (Siri-Trino et al., 2009). High-density lipoprotein (HDL) cholesterol (HDL-C) is inversely associated with CVD (Parish et al., 2012), while elevated LDL cholesterol (LDL-C) serum concentration is believed to strongly affect the CVD risk (Panagiotakos et al., 2004). It has later been shown that the inverse relationship between HDL-C levels and inflammatory markers illustrates the emerging role of HDL-C as an anti-inflammatory agent in reducing cardiovascular risk (Chrissohoou et al., 2007). It is known that diet modifies the lipid profile, but there are also data suggesting that the composition (quality fat diet) may be more important than the amount of fat per $s e$, which has an important effect on CVD mortality (Chahoud et al., 2004). The Mediterranean diet has long been reported to protect against the occurrence of several different negative health outcomes (Trichopoulou et al., 2003; Knoops et al., 2004; SerraMajem et al., 2004; Trichopoulou et al., 2005; Haveman-Nies et al., 2006) and conformity with the Mediterranean dietary pattern is associated with a reduction in mortality (Mitrou et al., 2007) and prevention of developing CVD (Trichopoulou et al., 2003). It has been observed that a 2-point adherence increase on a Mediterranean Diet Scale (Sofi et al., 2010) is associated with a significant reduction in overall mortality with a relative risk (RR) $=0.92(95 \% \mathrm{CI}: 0.90,0.94)$ and CVD incidence or mortality (RR $=0.90 ; 95 \%$ CI: $0.87,0.93)$. The effect on the lipid profile by to the Mediterranean diet has been evaluated in RCTs as well as nonrandomised clinical trials, prospective cohort studies and a crosssectional study. These studies demonstrate a decrease in total cholesterol (Ambring et al., 2004; Estruch et al., 2006), in LDL-C (Ambring et al., 2004; Vincent-Baudry et al., 2005) and in triglyceride levels (Ambring et al., 2004; Vincent-Baudry et al., 2005; Estruch et al., 2006), as well as an increase in HDL-C levels (Estruch et al., 2006). Socio-economic differences in the intake of fat have consistently been reported in Europe, e.g., a positive relationship between socio-economic status and healthier behaviour, including dietary habits, has been found (De Irala-Estevez et al., 2000). Indeed, people with a higher socio-economic status are more likely to have a higher consumption of fresh fruits and vegetables and a lower intake of fat compared with those with lower levels of income and/or education (Lopez-Azpiazu et al., 2003).

In Europe, major differences in geographic regions regarding CVD-related mortality have been observed with high mortality in eastern and northeastern countries and a lower CVD mortality in southern countries (Muller-Nordhorn et al., 2008; Deckert et al., 2010; Scarborough et al., 2011). This has been attributed to several cultural and behavioural differences between the populations, including diet composition (Da Silva et al., 2009). People in Spain are very aware of the Mediterranean diet and its health benefits. However, dietary patterns differ according to geographical area, mainly due to climatic, cultural or traditional factors. The differences in nutrient intake observed seem to be related to cardiovascular events and, therefore, also to CVD-related mortality. The aim of this study was to describe the expected relationship between the rates of CVD mortality, lipid profile and nutrient intake. We used geospatial models because they allow description and analysis of a variety of spatial patterns, mostly in cases characterised by low rates of CVD-related mortality.

\section{Materials and Methods}

\section{Study design and sample size}

This was an observational and descriptive study of an historical cohort, i.e. the large Spanish CVD study Dieta y Riesgo de Enfermedades Cardiovasculares en España (DRECE) composed of a representative sample of the Spanish general population, for which selection and sampling have been previously described (Ballesteros-Pomar et al., 2000). The DRECE cohort comprised 4,783 subjects, who were followed from 1991 to 2010. At the start of the study, the cohort age range was from 5 to 60 years. All subjects comprising the DRECE cohort underwent medical examination including laboratory tests as well as a personal interview and responded to a nutritional and physical activity questionnaire. Until now, five cross-sectional studies have been done along with the ascertainment of vital status and cause of death follow-up on the entire cohort. Vital statistics and causes of mortality are provided annually by the Spanish National Institute of Statistics.

\section{Variables and measures}

Four data groups were gathered.

First, anthropometric and demographic data, such as age, gender, height, weight.

Second, baseline clinical and epidemiological data, such as basic physical examination (including blood pressure and heart rate) and lipid profile (including total cholesterol, total triglycerides, HDL-C and LDL-C).

Third, baseline nutritional data, for which a dietary habits survey was conducted through the application of a questionnaire on the frequency of consumption of food (CFCA) developed and validated for the adult Spanish population (Martin-Moreno et al., 1993). Fourth, mortality data for all causes based death certificates provided by the National Institute of Statistics (INE) in Spain.

\section{Statistics}

The obtained information was entered into a computerised support by standardised procedures with regular quality controls. Statistical treatment of data started with a descriptive analysis. Quantitative variables were summarised by mean and standard deviation (SD). Lipid profile comparison between individuals who died due to CVD was carried out by the Mann-Whitney test (Hart, 2001). In addition, descriptive analysis was stratified by geographical area, and comparisons were made by the Kruskal-Wallis test (Kruskal and Wallis, 1953).

\section{Bayesian geospatial model}

With regard to geographical analysis, in the area of statistical modelling of spatial data, the use of hierarchical spatial models in a Bayesian framework has become widespread since the 1990's, mainly in cases of outcomes with low incidence rates, as in our case. For that reason, we used an extension of the hierarchical Bayesian model proposed by Richardson et al. (2006). First, we considered the following approach:

$$
\begin{array}{ll}
O_{1 i} \sim \text { Poisson }\left(m_{1 i}\right) ; R R_{1 i}=\frac{m_{1 i}}{e_{1 i}} & O_{2 i} \sim \text { Poisson }\left(m_{2 i}\right) ; R R_{2 i}=\frac{m_{2 i}}{e_{2 i}} \\
\log \left(m_{1 i}\right)=\log \left(e_{1 i}\right)+\alpha_{1}+\mu_{1 i} & \log \left(m_{2 i}\right)=\log \left(e_{2 i}\right)+\alpha_{2}+\mu_{2 i}
\end{array}
$$

where $O_{1 i}, O_{2 i}$ with $i=1, \ldots, n$ are the observed number of CV deaths and the lipid profile or diet intake, respectively, and $e_{1 i}, e_{2 i}$ with $i=1, \ldots, n$ the expected number of cases for both. The $\alpha$ values here 
are the specific factors and the space structure was introduced in the log scale by the joint structure of $\mu_{1 i}$ and $\mu_{2 i}$. In this particular case we have:

$$
\left(\begin{array}{l}
\mu_{1 i} \\
\mu_{2 i}
\end{array}\right) \sim \operatorname{MVN}\left(\left(\begin{array}{l}
\eta_{1 i} \\
\eta_{2 i}
\end{array}\right), \Sigma^{-1}\right)
$$

The CVD mortality rate and each of diet intake or lipid profile in this model were divided into three spatial components, the first of which common for both and the others specific to each of them (the latter shown in the Results section).

$$
\begin{array}{ll}
\eta_{1 i}=\lambda_{i} \delta+\phi_{1 i} ; & R R_{\phi 1}=\exp \left(\mu_{1 i}-\eta_{1 i}\right) \\
\eta_{2 i}=\frac{\lambda_{i}}{\delta}+\beta_{i}+\phi_{2 i} ; & R R_{\phi 2}=\exp \left(\mu_{2 i}-\eta_{2 i}\right)
\end{array}
$$

where $\lambda_{i}$ represents the shared spatial pattern and $\beta_{i}$ the differential spatial pattern between the CVD mortality rate and lipid profile/diet intake. Inference was made by using Markov Chain Monte Carlo (MCMC) simulations that provide an estimate of the posterior distributes of the model parameters. The choice of prior distribution for the model was the following:

$$
\begin{aligned}
& \alpha_{1}, \alpha_{2} \propto 1 \\
& \lambda \sim \operatorname{CARNormal}\left(\mathbf{W}, \tau_{\lambda}\right) \boldsymbol{\beta} \sim \text { CARNormal }\left(\mathbf{W}, \tau_{\beta}\right) \quad \tau \text { 's } \sim \operatorname{Gamma}(0.5,0.0005) \\
& \log (\delta) \sim N(0,0.2) \\
& \left(\begin{array}{l}
\phi_{1 i} \\
\phi_{2 i}
\end{array}\right) \sim M V N\left(\left(\begin{array}{l}
0 \\
0
\end{array}\right), \Sigma^{-1}\right) \quad \mathbf{\Sigma}^{-1} \sim \text { Wishart }\left(\left(\begin{array}{cc}
0.01 & 0 \\
0 & 0.01
\end{array}\right), 2\right)
\end{aligned}
$$

The statistical analyses were conducted using STATA 9.1/SE (Stata Corp, College Station, TX, USA), R, v. 4.1 (R Core Team, 2013) and Winbugs, v. 1.4 (The BUGS Project, 2007).

\section{Results}

Out of the 4,786 Spanish individuals making up the DRECE cohort, 220 subjects (148 men and 72 women) died (4.62\%) during the course of the study. Thirty-two of these deaths were CVDrelated. The mean age of people who died from cardiovascular causes was 61.08 years 95\% CI (57.47-64.69) and 70.91\% of them were males. Amongst males, the mean age was 58.58 years $95 \% \mathrm{CI}$ (54.11-63.05) and amongst the females 66.54 years 95\% CI (60.90-72.18).

Analysing lipid profile in both groups (Figure 1), we observed that total cholesterol as well as LDL-C and triglycerides were associated with CVD mortality with the highest levels in the group of people who died. On the other hand, there was an inverse relationship with HDL-C with lower concentrations in the mortality group compared with the survival group, i.e. $50.35 \mathrm{mg} / \mathrm{dL}$ versus 55.12 $\mathrm{mg} / \mathrm{dL}(\mathrm{P}=0.049)$.

Table 1 shows the nutrients consumption and the lipid profile by geographical area. The central and southern areas of the country stand out as having the worse lipid profiles and a high rate of fat intake. The spatial geographical analysis showed the relationship with CVD mortality in the different areas. Figure 2 shows a fat intake distribution very similar to that of the mortality rate and, similarly, in Figure 3, we see the least acceptable lipid profile in those areas together with the highest CVD-related mortality rate. However, we found a high variability within the country with respect to mortality and the nutritional food intake and lipid profile rates of regions. Large discrepancies are still observed among the

\begin{tabular}{|c|c|c|c|c|c|c|c|c|c|}
\hline & \multirow[b]{2}{*}{ North-West } & \multirow[b]{2}{*}{ North } & \multicolumn{3}{|c|}{ Geographical areas } & \multirow[b]{2}{*}{ East } & \multirow[b]{2}{*}{ South } & \multirow[b]{2}{*}{ Canary islands } & \multirow[t]{2}{*}{$\mathbf{P}$} \\
\hline & & & North-East & West & Centre-South & & & & \\
\hline BMI & $24.54(4.80)$ & $23.54(4.49)$ & $24.47(4.67)$ & $23.67(4.49)$ & $24.09(5.09)$ & $24.18(4.75)$ & $24.81(5.68)$ & $24.28(5.52)$ & 0.002 \\
\hline Carbohydrates & $288.33(102.58)$ & $282.08(90.58)$ & $322.83(101.42)$ & $333.06(108.76)$ & $300.56(98.60)$ & $285.91(115.44)$ & $269.06(104.42)$ & $310.43(102.74)$ & $<0.001$ \\
\hline Proteins & $112.34(3.22)$ & $107.41(27.54)$ & $120.27(35.31)$ & $119.01(30.09)$ & $118.39(31.80)$ & $117.57(40.21)$ & $110.98(39.89)$ & $111.88(33.56)$ & $<0.001$ \\
\hline Fats & $107.37(40.68)$ & $110.56(40.32)$ & $120.52(45.26)$ & $110.06(38.43)$ & $117.72(43.53)$ & $127.36(52.91)$ & $125.50(49.04)$ & $127.80(51.15)$ & $<0.001$ \\
\hline Kilocalories & 2702 (801.41) & $2660.72(731.33)$ & $2893.98(830.54)$ & $2946.14(829.34)$ & $2864(801.73)$ & 2742 (981.34) & $2621.29(912.18)$ & $2882.06(846.43)$ & $<0.001$ \\
\hline Total cholesterol & $189.27(42.44)$ & $192.41(43.42)$ & $190.98(45.90)$ & $187.28(43.19)$ & $187.88(40.97)$ & $197(45.93)$ & $196.26(43.24)$ & $194.48(46.80)$ & $<0.001$ \\
\hline HDL cholesterol & $56.73(13.91)$ & $56.18(13.809$ & $53.60(13.98)$ & $57.49(14.09)$ & $55.89(13.40)$ & $54113(13.26)$ & $54.03(13.64)$ & $51.69(12.89)$ & $<0.001$ \\
\hline LDL cholesterol & $113.17(36.69)$ & 116.88 (38.27) & $117.86(39.41)$ & 110.79 (38.33) & $112.94(36.08)$ & $120.88(39.53)$ & $120.22(37.01)$ & $118.68(36.56)$ & $<0.001$ \\
\hline Triglycerides & $105.32(70.41)$ & $100.21(60.65)$ & $102.63(80.43)$ & 104.98 (112.16) & $103.78(106.38)$ & $118.99(90.35)$ & $112.47(83.36)$ & $119.98(76.55)$ & $<0.001$ \\
\hline
\end{tabular}
different regions or areas in the macro-nutrients intake (SerraMajem et al., 1993; Varela-Moreiras et al., 2013). With respect to differences between geographic areas by the total energy intake,

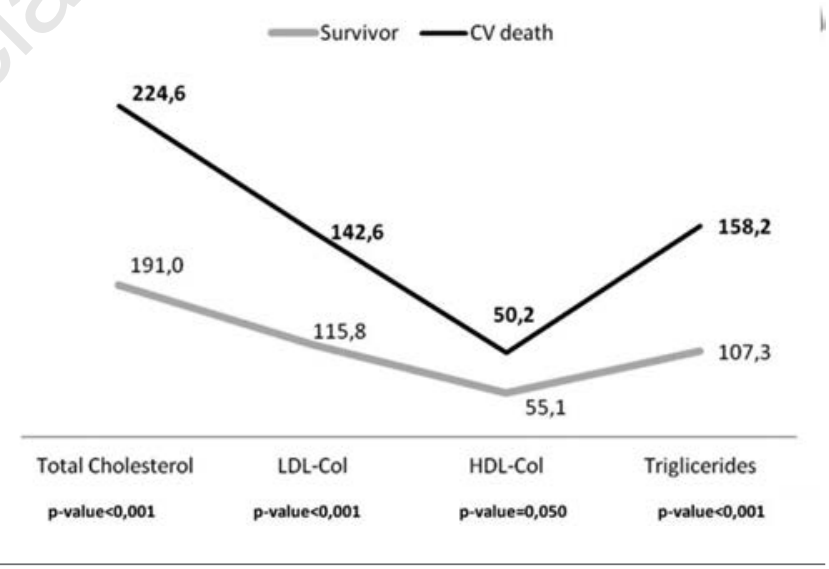

Figure 1. Lipid profile by cardiovascular mortality.

Table 1. Diet intake and lipid profile characteristics by region.

BMI, body mass index; HDL, high-density lipoprotein; LDL, low-density lipoprotein. 


\section{Discussion}

we noted that there was a percentage difference between geographic areas from $9.4 \%$ in total energy intake. The average caloric intake had a range of $2,660 \mathrm{kcal} /$ day in the North to $2,946 \mathrm{kcal} /$ day in the West. The caloric intake in these parts of the country was mainly in the form of carbohydrates, while in the Canaries, there was a higher fat intake. The percentage difference between geographic areas in fat intake was $15 \%$, in carbohydrate intake $19 \%$ and in protein intake $10.8 \%$. The areas with the highest fat intake were in the South, in the East and in the Canaries, while there was less consumption in the western and northern regions of the country. A clear gradient between regions in Spain with regard to intake of proteins or carbohydrates seems to have become established resulting in a north-south and east-west gradient with respect to fat intake.

As shown on Figures 2 and 3, there is a gradient of CVD-related mortality in the direction northwest to southeast. The geographical distribution of the cardiovascular mortality showed an aggregation in the South (11 deaths) and in the East (7 deaths) as well as in the south-eastern region (4 deaths) of the country, near areas with a history of adherence to healthy diet habits were observed. On the other hand, the regions with greater adherence to a recommended healthy diet had lower mortality in the northern and western parts of Spain. Adherence to nutritional recommendations related mainly to the western area (Castilla-León), which is characterised by a high intake of carbohydrates and proteins with comparatively little fat, and also by a relatively low mortality. Meanwhile, areas in the South and East (Andalusia, Extremadura, Murcia and Levante) showed the opposite situation, i.e. a higher mortality and a dietary pattern with high consumption of fats low in carbohydrates and proteins. We found the variables related to a low mortality to be i) a less aged population (OR $0.93,95 \% \mathrm{CI}$ 0.89-0.99); ii) a contextual dietary pattern marked by high contents of fish (OR 2.13, 95\% CI 1.38-3.28) and wine consumption (OR $1.50,95 \%$ CI 1.08-2.07); and iii) a low prevalence of obesity (OR $0.47,95 \%$ CI $0.22-1.01$ ). No significant associations were found with frequencies of arterial hypertension, hypercholesterolemia or smoking and socioeconomic factors.
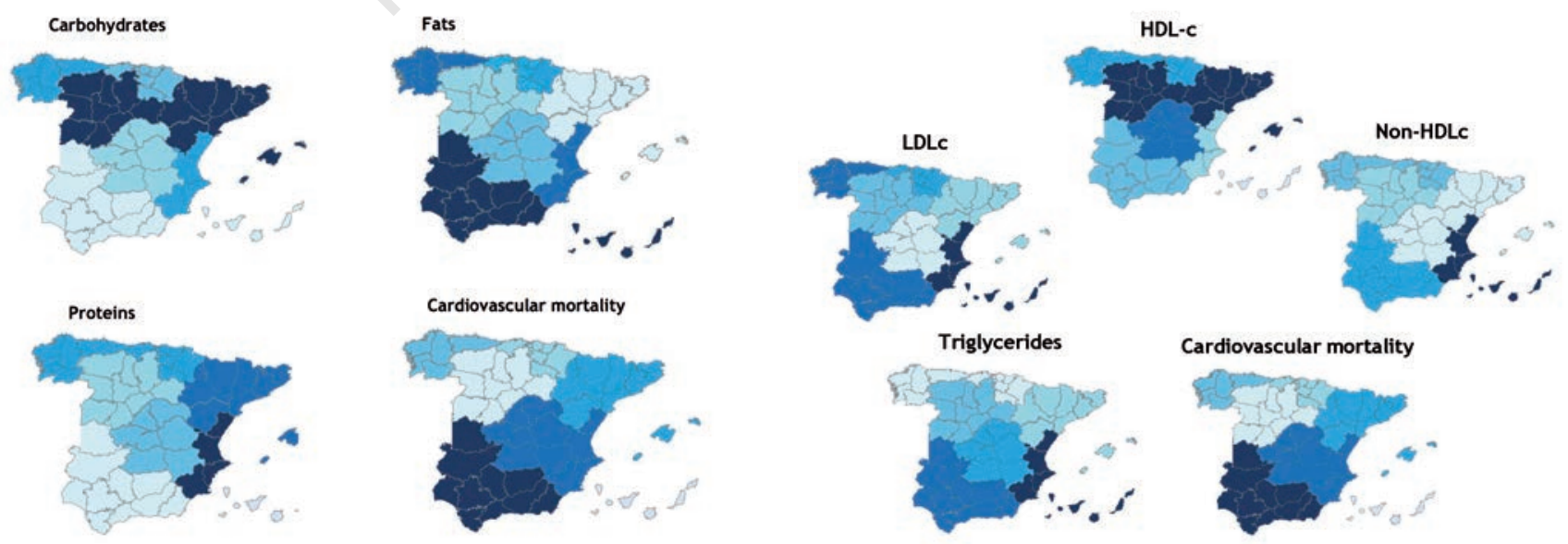

Figure 2. Variation of macronutrient intake in Spanish geograph-

Figure 3. Variation of lipid profile in Spanish geographical areas. ical areas. 
ing the same geographical areas associated with lower cardiovascular mortality, although analysed from another perspective and with the application of another methodology to assess the effect of diet on cardiovascular mortality. Geographical areas with higher mortality are located on the Mediterranean coast, which at first might seem surprising as they are supposed to be more deeply linked with the culture and traditions of greater adherence to the recommended quality diet. However, this may be changing as studies examining adherence to the Mediterranean diet in the Spanish adult population and its evolution over time describe a modification of nutritional habits (Bach-Faig et al., 2011; León-Muñoz et al., 2012). Indeed, the ENRICA (Rodríguez-Artalejo et al., 2011) study described the diet in Spain as being rich in proteins and total fat (mostly unsaturated fat) and somewhat low in carbohydrates found a low accordance between the diet of the Spanish population and the Mediterranean diet (46\%) with the goal set in MEDAS $>7$ (León-Muñoz et al., 2012), which confirms that Spaniards are drifting away from the Mediterranean diet to progressively adopt a less healthy diet. In another study, the progressive replacement of carbohydrates by proteins and fats is clearly described ending with the conclusion that Food consumption patterns in Spain and energy and nutrient intakes have changed markedly in the last 40 years, differing at present from the traditional and healthy Mediterranean diet (Varela-Moreiras et al., 2010). Indeed, these change are not only observed in Spain, but also in the rest of the world: throughout the last four decades the Mediterranean countries have moved away from the Mediterranean dietary pattern at the order of $42.5 \%$. Within the Mediterranean area, the European countries are primarily responsible for this loss of adherence with changes in cultural, social and political factors likely to have had a heavy influence on changes in food habits. On the other hand, many countries in northern Europe and some other countries around the world are adopting the Mediterranean-like dietary pattern (Da Silva et al., 2009).

Income and economic environment assume a crucial role in the context of dietary pattern changes (De Irala-Estevez et al., 2000; Vareiro et al., 2009). Factors such as cultural differences, personal taste and traditions, education, geographic location, access to technology as well as health and health attitudes influence food preferences and food availability (Trichopoulou et al., 2002). The fact that the availability of several Mediterranean dietary components, such as fruits, vegetables and olive oil, has increased (or been maintained) could have led to a greater adherence to the Mediterranean dietary pattern. Contrary, however, the availability of the non-Mediterranean foods have increased to a much greater extent compared to Mediterranean foods (Da Silva et al., 2009). In our study, the lipid profiles differences between regions and the geographical distribution of macronutrients intake, mainly fats, were associated with cardiovascular mortality rates but did not fully explain the regional variation of these rates because they are not explained by the type of fat consumed. In areas or regions with high fat intake, this may be at the expense of mainly saturated fat as it is correlated with increased cardiovascular mortality and a less acceptable lipid profile (Cabrera et al., 2012; Hooper et al., 2012).

In a study, based on the identification of regions with lower mortality, socioeconomic factors showed no effect or association with mortality (Trichopoulou et al., 2002). However, the educational and cultural level factors were analysed in the EPIC study (Gonzalez et al., 2002); no significant differences were observed in adherence to this pattern in relation to educational level and social class. The Mediterranean dietary pattern appears to be evenly distributed between socioeconomic and demographic groups (Gonzalez et al., 2002). No significant differences were observed in the adhesion score in relation to educational level, some differences are instead related to the social class of origin (Gonzalez et al., 2002). This, though not necessarily representing the respondent's social class, expresses a past period (childhood and youth), which have a primary role in the acquisition of food habits of the adult. It has been demonstrated that if low saturated fat dietary counselling starts in infancy, it has a significant favourable effect on dietary saturated fat intake and on serum lipid values through childhood and adolescence extending to early adulthood (Maruthur et al., 2009; Siri-Trino et al., 2010; Niinikoski et al., 2012). Nutrition policy actions to tackle dietary westernisation and preserve the healthy dietary pattern are required to be designed and adapted to different populations groups to improve the situation (Da Silva et al., 2009; Hooper et al., 2012). Awareness campaigns to encourage a healthy diet have proven to be an effective strategy, and can be maintained over time (Wister et al., 2007). This can be achieved by using the media, as in the MOLI-SANI project (Bonnacio et al., 2012), a population-based cohort study to investigate the association between mass media information, dietary habits and CVD risk factors in 1,132 Italian adults. Exposure to mass media information is significantly associated with greater adherence to both a Mediterranean diet and a Mediterranean-eating pattern (Bonnacio et al., 2012). With regard to the extrapolation of our results to the general population, it should be noted that they are based on a representative sample of the Spanish population with a high level of participation from all social levels and geographic areas. Although we did not analyse the effect of socioeconomic status or education, we suggest that the recommended food accessibility is not dependent on cost and that the nutritional pattern acquired by the population does not differ due to these causes. Furthermore, when assessing food consumption, a potential bias must be taken into account, i.e. the potential recall bias introduced by respondents in reporting their diets connected with a tendency to overestimate food consumption accepted as healthy and underestimate the least healthy food.

\section{Conclusions}

Areas with increased cardiovascular mortality are located in the Spanish South and East, while lower mortality was predominantly found in the North and Northwest of the country with established risk strata coinciding with the level of fat intake. The observed north-south gradient of low to high cardiovascular mortality associated with dietary patterns considered as healthy confirms the role of inadequate fat intake and its contribution to CVDrelated mortality. According to the distribution of macronutrients, two diet-related CVD mortality risk strata can be distinguished. In the Northwest and Southeast specific intervention strategies aimed at modifying nutritional/dietary habits to strengthen, improve and restore recommended nutritional habits, should be implemented.

\section{References}

Ambring A, Friberg P, Axelsen M, Laffrenzen M, Taskinen MR, Basu S, Johansson M, 2004. Effects of a Mediterranean- 
inspired diet on blood lipids, vascular function and oxidative stress in healthy subjects. Clin Sci (Lond.) 106:519-25.

Bach-Faig A, Fuentes-Bol C, Ramos D, Carrasco JL, Roman B, Bertomeu I, Cristiá E, Geleva D, Serra-Majem L, 2011. The Mediterranean diet in Spain: adherence trends during the past two decades using the Mediterranean Adequacy Index. Public Health Nutr 14:622-8.

Ballesteros-Pomar MD, Rubio-Herrera MA; Gutiérrez-Fuentes JA; Gómez-Gerique JA, Gómez-de-la-Cámara A, Pascual O, Gárate I, Montero R, Campiña S, 2000. Dietary habits and cardiovascular risk in the Spanish population: the DRECE study (I). Diet and cardiovascular events risk in Spain. Ann Nutr Metab 44:108-14.

Bonaccio M, Di Castelnuovo A, Costanzo S, De Lucia F, Olivieri M, Donati MB, de Gaetano G, Iacoviello L, Bonanni A, 2012. Mass media information and adherence to Mediterranean diet: results from the Moli-sani study. Int J Public Health 57:589-97.

BUGS Project, 2007. WinBUGS (Version 1.4), Cambridge, UK Available from: http://www.mrc-bsu.cam.ac.uk/software/bugs/

Cabrera M, de Andrade SM, Dip RM, 2012. Lipids and all-cause mortality among older adults: A 12 follow-up Study. Scientific World J 2012:930139.

Chahoud G, Aude YW, Mehta JL, 2004. Dietary recommendations in the prevention and treatment of coronary heart disease: do we have the ideal diet yet. Am J Cardiol 94:1260-7.

Chrissohoou C, Pitsavos C, Skoumas J, Masoura C, Katinioti A, Panagiotakos D, Stefanadis C, 2007. The emerging antiinflammatory role of HDL-Cholesterol, illustrated in cardiovascular disease free population: the ATTICA study. Int J Cardiol 122:29-33.

Da Silva R, Bach Faig A, Raidó Quintana B, Buckland G, Vaz de Almeida MA, Serra-Majem L, 2009. Worldwide variations of adherence to the Mediterranean diet in 1961-1965 and 20002003. Public Health Nutr 12:1676-84.

Deckert A, Winkler V, Paltiel A, Razum O, Becher H, 2010. Time trends in cardiovascular disease mortality in Russia and Germany from 1980 to 2007 - are there migration effects? BMJ Public Health 10:488.

De Irala-Estevez J, Groth M, Johansson L, Oltersdorf U, Prättalä R, Martínez-González MA, 2000. A Systematic review of socio-economic differences in food habits in Europe: consumption of fruit and vegetables. Eur J Clin Nutr 54:706-14.

Estruch R, Martínez-González MA, Corella D, Salas-Salvadó J, Ruiz-Gutiérrez V, Covas MI, Fiol M, Gómez-Gracia E, LópezSabater MC, Vinyoles E, Arós F, Conde M, Lahoz C, Lapetra J, Sáez G, Ros E, PREDIMED Study Investigators, 2006. Effects of a Mediterranean-style diet on cardiovascular risk factors: A randomized trial. Ann Intern Med 145:1-11.

Gabriel R, Alonso M, Segura A, Tormo MJ, Artigao LM, Banegas JR, Brotons C, Elosua R, Fernández-Cruz A, Muñiz J, Reviriego B, Rigo F, 2008. Prevalencia, distribución y variabilidad geográfica de los principales factores de riesgo cardiovascular en España. Análisis agrupado de datos individuales de estudios epidemiológicos poblacionales: estudio ERICE. Rev Esp Cardiol 61:1030-40.

Gónzalez CA, Argilaga S, Agudo A, Amiano P, Barricarte A, Beguiristain JM, Chirlaque MD, Dorronsoro M, Martínez C, Navarro C, Quirós JR, Rodríguez M, Tormo MJ, 2002. Diferencias sociodemográficas en la adhesión al patrón de dieta mediterránea en poblaciones de España. Gac Sanit $16: 214-21$
Grau M, Elosua R, Cabrera de León A, Guembe MJ, Baena-Díez JM, Vega Alonso T, Félix FJ, Zorrilla B, Rigo F, Lapetra J, Gavrila D, Segura A, Sanz H, Fernández-Bergés D, Fitó M, Marrugat J, 2011. Factores de riesgo cardiovascular en España en la primera década del Siglo XXI: Análisis agrupado con datos individuales de 11 estudios de base poblacional, estudio DARIOS. Res Esp Cardiol 64:295-304.

Hart A, 2001. Mann-Whitney test is not just a test of medians: differences in spread can be important. Brit Med J 323:391-3.

Haveman-Nies A, de Groot LP, Burema J, Cruz JA, Osler M, van Staveren WA, 2002. Dietary quality and lifestyle factors in relation to 10-year mortality in older Europeans: the SENECA study. Am J Epidemiol 156:962-8.

Hooper I, Summerbell CD, Thompson R, Sills D, Roberts FG, Moore HJ, Smith D, 2012. Reduced or modified dietary fat for preventing cardiovascular disease. Cochrane Database Syst Rev 16:CD002137.

Kaluza J, Hakansson N, Brzozowska A, Wolk A, 2009. Diet quality and mortality: a population -based prospective study of men. Eur J Clin Nutr 63:451-7.

Kattainen A, Salomaa V, Harkanen T, Jula A, Kaaja R, Antero Kesäniemi Y, 2006. Coronary heart disease: from a disease of middle-aged men in the late 1970 s to a disease of elderly women in the 2000s. Eur Heart J 27:296-301.

Knoops KT, de Groot LC, Kromhout D, Perrin AE, MoreirasVarela O, Menotti A, van Staveren WA, 2004. Mediterranean diet, lifestyle factors, and 10-year mortality in elderly European men and women: the HALE project. J Am Stat Assoc 292:1433-9.

Kruskal WH, Wallis WA, 1952. Use of ranks in one-criterion variance analysis. J Am Med Assoc 47:583-621.

León-Muñoz L, Guallar-Castillón P, Graciani A, López-García E, Mesas AE, Aguilera MT, Banegas JR, Rodríguez-Artalejo F, 2012. Adherence to the Mediterranean Diet Pattern has declined in Spanish adults. J Nutr 142:1843-50.

Lopez-Azpiazu I, Sanchez-Villegas A, Johansson L, Petkeviciene J, Prattala R, Martinez-Gonzalez MA, 2003. Disparities in food habits in Europe: systematic review of educational and occupational differences in the intake of fat. J Hum Nutr Diet 16:349-64.

Lunn DJ, Thomas A, Best N, Spiegelhalter D, 2000. WinBUGS a Bayesian modelling framework: concepts, structure, and extensibility. Stat Comput10:325-37.

Mann HB, Whitney JR, 1947. On a test of wether one of two random variables is stochastically largers than the other. Ann Math Stat 22:125-8.

Marrugat J, Elosua R, Aldasoro E, Tormo MJ, Vanaclocha H, Segura A, Fiol M, Moreno-Iribas C, Pérez G, Arteagoitia JM, Cirera L, Cabadés A, Vega G, Avestarán JI, García V, Hurtadode-Saracho I, García J, Zurriaga O, Muñiz J, Sala J, Isquemia Coronaria Aguda Investigators, 2004. Regional variability in population acute myocardial infarction cumulative incident and mortality rates in Spain 1997 and 1998. Eur J Epidemiol 19:831-9.

Martin-Moreno JM, Boyle P, Gorgojo L, Maisonneuve P, Fernandez-Rodriguez JC, Salvini S, Willett WC, 1993. Development and validation of a food frequency questionnaire in Spain. Int J Epidemiol 3:512-9.

Medrano MJ, Boix R, Palmera A, Ramis R, Galán I, López-Abente G, 2012. Towns with extremely low mortality due to ischemic heart disease in Spain. BMC Public Health 12:174 
Mente A, de Koning L, Shannon HS, Anand S, 2009. A systematic review of the evidence supporting a causal link between dietary factors and coronary heart disease. Arch Intern Med 169:659-69.

Mitrou P, Kipnis V, Thiébaut A, Reedy J, Subar AF, Wirfált E, Flood A, Mouw T, Hollenbeck AR, Leitzmann MF, Schartzkin A, 2007. Mediterranean dietary pattern and prediction of all cause mortality in a US population. Results from the NIHAARP diet and health study. Arch Intern Med 167:2461-8.

Moreno R, 2001. Management of acute myocardial infarction in Spain. Current inter-regional differences according to IBERICA Registry. Rev Esp Cardiol 54:419-21.

Müller-Nordhorn J, Binting S, Roll S, Willicn SN, 2008. An update on regional variation in cardiovascular mortality within Europe. Eur Heart J 29:1316-26.

Niinikoski H, Pahlkala K, Ala-Korpela M, Viikari J, Rönnemaa T, Lagström H, Jokinen E, Jula A, Savolainen MJ, Simell O, Raitakari OT, 2012. Effect of repeated dietary counseling on serum lipoproteins from infancy to adulthood. Pediatrics 129:e704.

Panagiotakos DB, Pitsavos C, Chrysohoou C, Skoumas J, Stefanaides C, 2004. Status and management of blood lipids in Greek adults and their relation to sociodemografic, lifestyle and dietary factors: the ATTICA Study Blood Lipids distribution in Greece. Atherosclerosis 173:353-61.

Parish S, Offer A, Clarke R, Hopewell JC, Hill MR, Otvos JD, Armitage J, Collins R, Heart Protection Study Collaborative Group, 2012. Lipids and lipoproteins and risk of different vascular events in the MRC/BHF heart protection study. Circulation 125:2469-79.

R Core Team, 2013. R: A language and environment for statistical computing (Version 3.1). Vienna, Austria: R Foundation for Statistical Computing. Available from: http://www.rproject.org

Richardson S, Abellan JJ, Best N, 2006. Bayesian spatio-temporal analysis of joint patterns of male and female lung cancer risks in Yorkshire (UK). Stat Method Med Res 15:385-407.

Rodríguez-Artalejo F, Banegas-Banegas JR, Guallar-Castillón P, López-García E, Puente-Mendizabal M, Del-Rey Calero J, 2000. Distribución geográfica de las enfermedades cardiovasculares en España: La mortalidad es mayor en las regiones del sur y del mediterráneo. Cardiovascular Risk Factors 9:311-8.

Rodríguez-Artalejo F, Graciani A, Guallar-Castillón P, LeónMuñoz LM, Zuluaga MC, López-García E, Gutiérrez-Fisac JL, Taboada JM, Aguilera MT, Regidor E, Villar-Álvarez F, Banegas JR, 2011. Rationale and methods of the study on nutrition and cardiovascular risk in Spain (ENRICA)]. Rev Esp Cardiol 64:876-82.

Scarborough P, Morgan RD, Webster P, Rayner M, 2011. Differences in coronary heart disease, stroke and cancer mortality rates between England, Wales, Scotland and Northern Ireland: the role of diet and nutrition. BMJ Open 1:e000263.

Serra-Majem L, Ribas L, Lloveras G, Salleras L, 1993. Changing patterns of fat consumption in Spain. Eur J Clin Nutr 47:13-20.
Serra-Majem L, Trichopoulou A, Ngo de la Cruz J, Cervera P, García-Álvarez A, La Vecchia C, Lemtouni A, Trichopoulos D, 2004. International Task Force on the Mediterranean Diet. Does the definition of the Mediterranean diet need to be updated? Public Health Nutr 7:927-9.

Siri-Trino P, Sun W, Hu FB, Krauss RM, 2010. Saturated fat, carbohydrates and cardiovascular disease. Am J Clin Nutr 91:502-9.

Sofi F, Abbate R, Gensini GF, Casini A, 2010. Accruing evidence on benefits of adherence to the Mediterranean diet on health: an updated systematic review and meta-analysis. Am J Clin Nutr 92:1189-96.

StataCorp, 2009. Stata Statistical Software: Release 11. StataCorp LP, College Station, TX, USA.

Trichopoulou A, Costacou T, Bamia C, Trichopoulos D, 2003. Adherence to a Mediterranean diet and survival in a Greek population. New Eng J Med 348:2599-608.

Trichopoulou A, Naska A, Costacou T on behalf of the DAFNE III Group, 2002. Disparities in food habits across Europe. Proc Nutr Soc 61:553-8.

Trichopoulou A, Orfanos P, Norat T, Bueno-de-Mesquita B, Ocké MC, Peeters PH, van der Schouw YT, Boeing H, Hoffmann K, Boffetta P, Nagel G, Masala G, Krogh V, Panico S, Tumino R, Vineis P, Bamia C, Naska A, Benetou V, Ferrari P, Slimani N, Pera G, Martinez-Garcia C, Navarro C, Rodriguez-Barranco M, Dorronsoro M, Spencer EA, Key TJ, Bingham S, Khaw $\mathrm{KT}$, Kesse E, Clavel-Chapelon F, Boutron-Ruault MC, Berglund G, Wirfalt E, Hallmans G, Johansson I, Tjonneland A, Olsen A, Overvad K, Hundborg HH, Riboli E, Trichopoulos D, 2005. Modified Mediterranean diet and survival: EPICelderly prospective cohort study. BMJ 330:991.

Vareiro D, Bach-Faia A, Raidó-Quintana B, Bertomeu I, Buckland G, Vaz de Almeida MD, Serra-Majem L, 2009. Availability of Mediterranean and non-Mediterranean foods during the last four decades: comparison of several geographical areas. Publ Health Nutr 12:1667-75.

Varela-Moreiras G, Ávila JM, Cuadrado C, Del Pozo S, Ruiz E, Moreiras O, 2010. Evaluation of food consumption and dietary patterns in Spain by the Food Consumption Survey: Updated information. Eur J Clin Nutr 64(Suppl.3):37-43.

Varela-Moreiras G, Ruiz E, Valero T, Avila JM, del Pozo S, 2013. The Spanish diet: an update. Nutr Hosp 28(Suppl.5):13-20.

Vincent-Baudry S, Defoort C, Gerber M, Bernard MC, Verger P, Helal O, Portugal H, Planells R, Grolier P, Amiot-Carlin MJ, Vague P, Lairon D, 2005. The Medi-RIVAGE study: Reduction of cardiovascular disease risk factors after a 3-mo intervention with a Mediterranean-type diet or a low-fat diet. Am J Clin Nutr 82:964-71.

Wister A, Loewen N, Kennedy-Symonds H, McGowan B, McCoy B, Singer J, 2007. One-year follow-up of a therapeutic lifestyle intervention targeting cardiovascular disease risk. CMAJ 177:859-65.

Yarnell JW, Evans AE, 2000. The Mediterranean diet revisited towards resolving the French paradox. Q J Med 93:783-85. 